\title{
COMPARTMENT SYNDROME OF THE HAND AFTER LAPAROSCOPIC GYNECOLOGICAL SURGERY
}

\author{
*J. Rodriguez, *J. Torres, **V. Salinas, ${ }^{* * *}$ R. Pareja. \\ * Fellowship Oncology Gynecology, ** Fellowship Orthopedic Oncology, *** Gynecologist Oncologist \\ National Institute of Cancerology. Department of Oncological Gynecology.
}

Bogotá, Colombia.

E-mail: jaroldjhon@yahoo.com

\section{INTRODUCTION}

Acute compartment syndrome (ACS) of the hand is a potentially devastating and infrequent condition observed after trauma, arterial injury, or after prolonged compression of the upper limb. We present the case of a patient diagnosed with compartment syndrome of the hand after laparoscopic surgery for an epithelial ovarian cancer.

\section{CASE REPORT}

Patient of 42-year-old woman with incidental finding of high-grade ovarian serous carcinoma after an emergency surgery. On imaging evaluation, the patient was found to have evidence of residual retroperitoneal adenopathy and, was taken to the operating room for a staging procedure by laparoscopy. In the immediate postoperative period, she developed a compartment syndrome of the right hand that required multiple fasciotomies and multidisciplinary management by plastic surgery, orthopedics, and rehabilitation medicine. The patient was discharged from the hospital seven days after the laparoscopic surgery to undergo rehabilitation. Three months after surgery, she is continuing to recover, with near complete recovery of hand function. The patient has completed a total of three cycles of chemotherapy with carboplatin / paclitaxel.
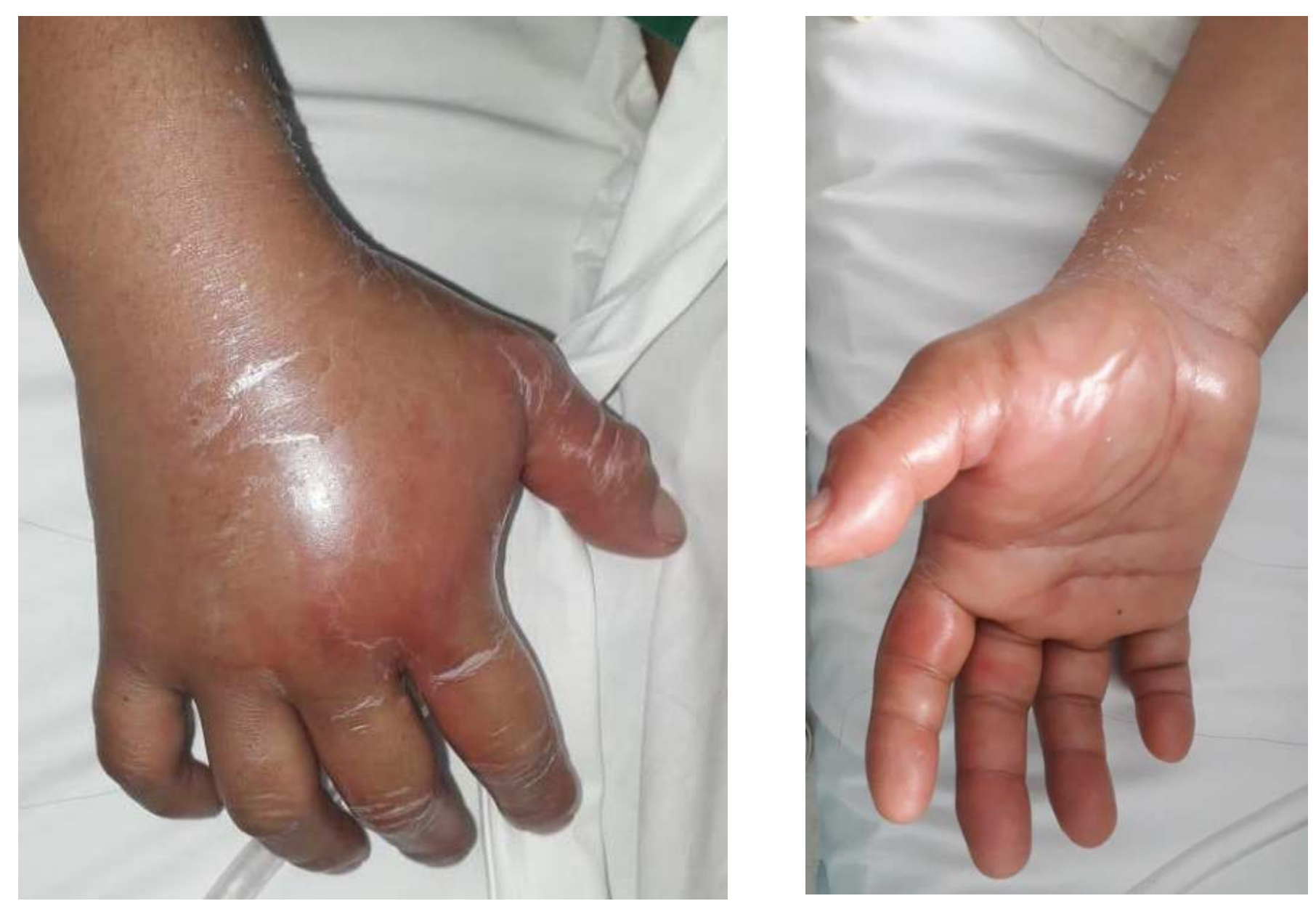

Immediate postoperative exam shows swelling in the right hand and erythema.

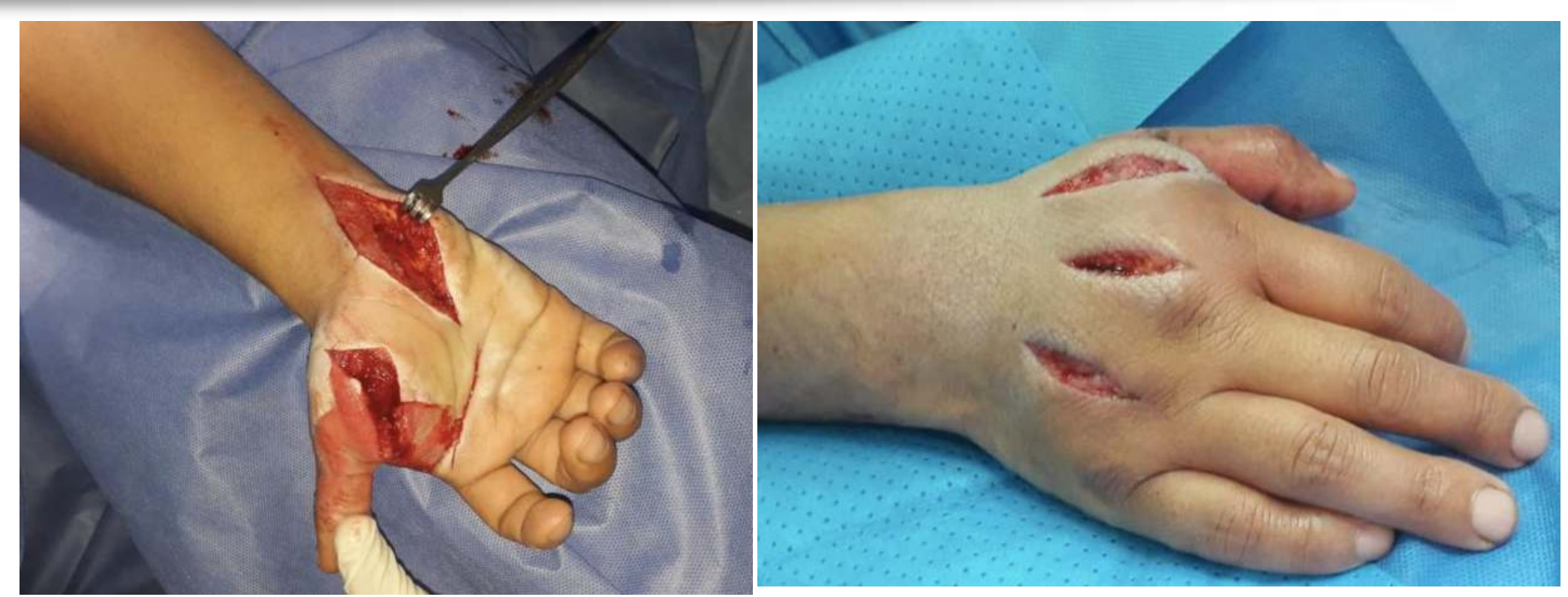

Fasciotomy performed over 2,3,4 to interosseous space, also incision on the volar side of the hand on the thenar space with ample fasciotomy.

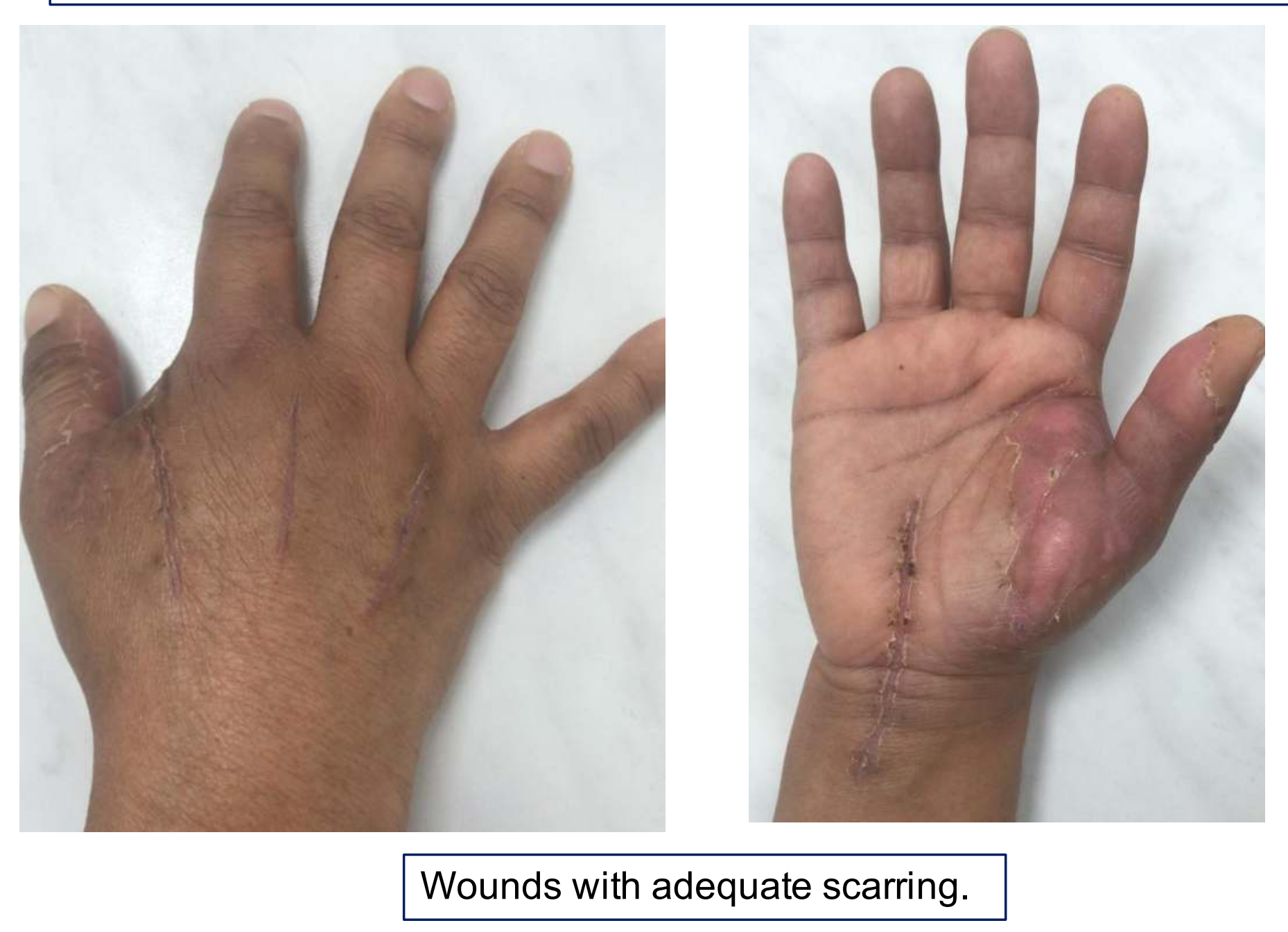

CONCLUSION

The compartment syndrome of the hand is an uncommon event but it can generate major functional deficits and even death if it is not diagnosed and treated in a timely manner.

Strict criteria for patient positioning in laparoscopy surgery may avoid or reduce this complication. To date this is the first case reporting such complication, associated with laparoscopic gynecologic surgery.

\section{REFERENCES}

- Rubinstein AJ, Ahmed IH, Vosbikian MM. Hand compartment synd rome. Hand Clin. 2018.34: $41-52$

- Prasarn ML, Ouellette EA. Acute Compartment Syndrome of the Upper Extremity: review article. J Am Acad Orthop Surg 2011;19: 49-58

- Codding JL, Vosbikian MM, llyas AM. Acute compartment syndrome of the hand. J Hand Surg Am 2015; 40:1213-6.

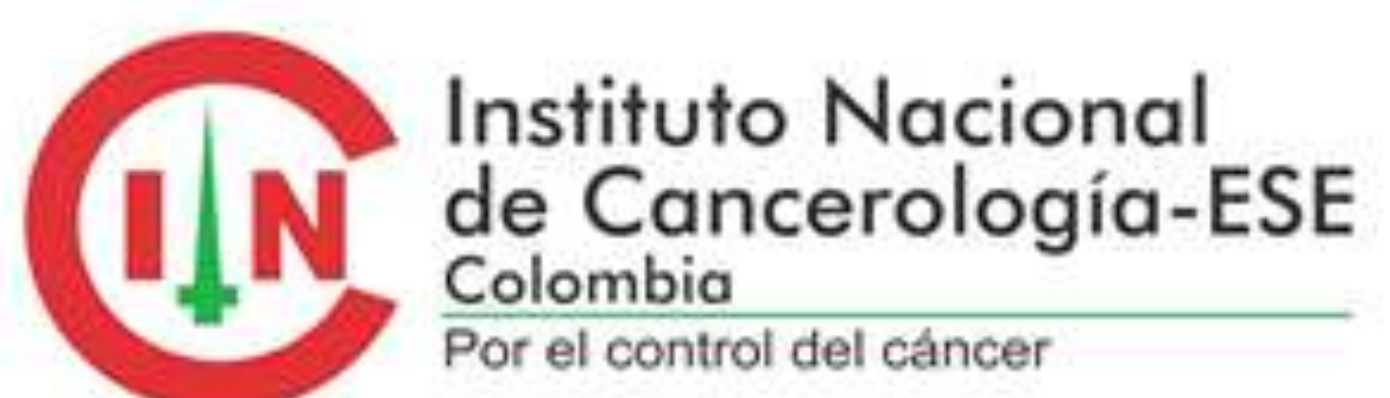

